\title{
REFLEXÕES ÉTICAS ACERCA DOS ESTUDOS DE SOROPREVELÊNCIA DE HEPATITES VIRAIS
}

\author{
Rosangela Gaze*; Diana Maul de Carvalho; Clara Fumiko Tachibana Yoshida; luiz Fernando Rangel Tura
}

Trabalho realizado no Núcleo de Estudos de Saúde Coletiva/ UFRJ

\author{
*Correspondência: \\ R. Teodoro da Silva, 751 \\ apto 504, BI. 02, Vila Isabel \\ Cep: 20560-000, Rio de \\ Janeiro, RJ \\ (21) $2598-9282$ \\ rgaze@nesc.ufri.br
}

\begin{abstract}
RESUMO
Introdução. A aplicação de novas tecnologias em pesquisas epidemiológicas sobre hepatites virais (HV) exige discussões éticas sobre inquéritos domiciliares de soroprevalência (IDS), estudos sentinelas (ES) e de registros de bancos de sangue (ERBS) e amostras de sorotecas (EAS).

Métodos. Discutem-se fatores de força (FF) e fragglidade (FR) destas abordagens, argumentos/justificativas para sua utilização e alternativas, segundo os princípios éticos da Resolução CNS ñ 196/96.

Resultados E Discussão. As pesquisas sobre HV justificam-se por sua magnitude, gravidade, vulnerabilidade e necessidade de subsidiar protocolos diagnósticos/terapêuticos e estratégias de prevenção/controle. Em relação aos IDS, discutimos quanto a FF: autonomia do sujeito; representatividade amostral adequada; e FR: custo maior que benefícios; possibilidade de obter a informação por outros meios. Para os ES, FF: monitoramento das HV com custo operacional inferior ao dos IDS; ausência de danos adicionais ao sujeito; e FR: limitação relativa de representatividade. Para os ERBS, FF: monitoramento do VHBNHC em doadores de sangue com baixo custo, sem risco adicional; e FR: limitação de representatividade. Quanto aos EAS, FF: preponderância de beneficios sobre riscos/custos; possibilidade de desvendar agravos desconhecidos e de oferecer diagnóstico precoce e tratamento; FR: material biológico e dados de uma pesquisa podem ser utilizados em outras.

Conclusão. Estas discussões contribuem para embasar processos éticos, orientar a escolha do tipo de estudo epidemiológico e construir novos conceitos sobre estes temas.

UnITERMOS: Hepatites. Ética. Soroteca; Inquérito.
\end{abstract}

\section{INTRODUÇÃo}

Os avanços tecnológicos têm proporcionado maior precocidade no diagnóstico de diversos agravos à saúde!. Ao lado das evidentes vantagens que podem trazer ao tratamento e prognóstico de doenças, acrescenta-se a maior oportunidade no conhecimento do comportamento epidemiológico de eventos adversos e na instituição de estratégias de prevenção. Métodos diagnósticos hoje disponíveis vêm viabilizando inclusive a detecção de infecções que cursam de forma assintomática, como as HV, cuja fração subclínica é mais significativa do que a reconhecida clinicamente ${ }^{2}$. E importante ressaltar que muitos destes recursos - de elevada sensibilidade para detectar doenças em grupamentos populacionais - nem sempre se acompanham de maior disponibilidade de recursos terapêuticos ou preventivos. Impõe-se, assim, a necessidade de discutir os aspectos éticos de pesquisas envolvendo seres humanos que utilizam estes recursos diagnósticos ${ }^{3}$.

Dois tipos de estudos são habitualmente utilizados na pesquisa epidemiológica de HV: os estudos transversais de soroprevalência (IDS) e os retrospectivos com dados de bancos de sangue ${ }^{4-8}$. Menos utilizados, mas ganhando espaço, encontram-se os ES, como a rede de médicos sentinelas para notificação de influenza, $\mathrm{HV}$, uretrites agudas, sarampo e caxumba na França e a vigilância das HV dos Centers for Disease Control and Prevention(CDC) dos Estados Unidos, tendo como sentinelas 12 estados notificadores, para monitorar casos agudos e identificar os fatores de risco mais freqüentes ${ }^{10}$. Menos difundida vem sendo a manutenção de sorotecas (coleção de soros armazenada sob refrigeração e organizada para estudo) a partir de amostras do sangue doado e do receptor. Estas coleções de amostras de soro humano têm sido extraordinariamente úteis na avaliação da transmissibilidade de diversos patógenos por via sangǘnea, como do vírus da hepatite $\mathrm{C}$, do HIV e do HTLVI". Poderão ainda ser usadas na determinaçãa da prevalência de novos agentes patogênicos e na estimativa do risco de transmissão por meio do sangue"!.

Este artigo tem como objetivo discutir os aspectos éticos de cada tipo de estudo, tendo como objeto as HV, à luz dos princípios e diretrizes da ética em pesquisa em seres humanos vigentes no país. Discute os principais FF e FR de cada metodologia, apontando argumentos e justificativas para sua utilização e alternativas para contornar as dificuldades apresentadas.

\section{Métodos}

São considerados os tipos de estudos especiais mais freqüentemente utilizados nas pesquisas epidemiológicas que têm por objetivo obter dados de incidência/ prevalência de HV: IDS, ES, ERBS (retrospectivos ou prospectivos) e EAS. Como, em sua maioria, estes estudos são realizados por instituições acadêmicas ou sociedades científicas, as questões éticas são discutidas considerando a equipe de pesquisa como externa às instituições governamentais responsáveis pela elaboração e execução das políticas de saúde. 
Os aspectos éticos envolvidos no desenvolvimento de cada um desses tipos de estudo são discutidos segundo os princípios éticos da Resolução CNS no 196/96'12. Estes princípios exigem que a pesquisa com seres humanos tenha relevância social, esteja justificada em termos metodológicos, garanta a autonomia, promova a beneficência e evite a maleficência para o sujeito e a comunidade pesquisados. Procurando manter a objetividade da discussão, dentro destes princípios, foram consideradas apenas as exigências relevantes para os estudos de prevalência de HV e que costumam suscitar polêmica, ou seja, a pesquisa deve ser realizada somente quando:

I. O conhecimento que se pretende obter não possa ser obtido por outro meio;

2. Haja preponderância de benefícios sobre riscos e custos, nas pesquisas de rastreamento;

3. For possível obter o consentimento livre e esclarecido (autonomia) do sujeito da pesquisa;

4. A metodologia for adequada;

5. Se disponha de recursos humanos e materiais suficientes para garantir o bem-estar do sujeito da pesquisa;

6. Haja segurança de confidencialidade e privacidade do sujeito da pesquisa na obtenção e divulgação das informações;

7. Haja respeito aos valores culturais, sociais, morais, religiosos e éticos, bem como aos hábitos e costumes das comunidades;

8. Haja garantia de benefícios, cujos efeitos possam permanecer, sempre que possível, após seu encerramento;

9. Haja garantia de retorno dos benefícios às pessoas e comunidades, inclusive comunicando às pessoas sobre a importância da mudança de hábitos/comportamentos, quando for o caso;

10. Seja assegurada a comunicação às autoridades sanitárias dos resultados da pesquisa, sempre que puderem contribuir para a melhoria das condições de saúde da coletividade;

II. Sejam asseguradas, aos sujeitos da pesquisa, as condições de acompanhamento, tratamento ou de orientação;

12. Seja assegurado que o material biológico e os dados obtidos na pesquisa serão utilizados, exclusivamente, para a finalidade prevista no protocolo.

As seguintes exigências foram consideradas como condições gerais para realização de uma pesquisa, não havendo nada espećífico a ser comentado em relação aos estudos de prevalência de HV: a inexistência de conflito de interesses entre o pesquisador, os sujeitos da pesquisa e o patrocinador do projeto, a clareza de participação dos pesquisadores no delineamento de estudos multicêntricos e a garantia de que o estudo só seja interrompido após análise do Comitê de Ética em Pesquisa (CEP). O retorno dos benefícios às pessoas e comunidades foi considerado como mais afeto à credibilidade das instituições de pesquisa e dos pesquisadores do que ao tipo de estudo, não se justificando discussões específicas. Considerações sobre os riscos às gestantes, mulheres em idade fértil, interferências sobre fertilidade, embrião, feto, recém-nascido, trabalho de parto, puerpério e lactação também não suscitam discussão específica, tendo em vista a reduzida importância ou inexistência destes riscos nos tipos de estudo em tela.

A garantia de que o material biológico e os dados obtidos na pesquisa sejam utilizados, exclusivamente, para a finalidade prevista no protocolo ${ }^{12}$ é um dos aspectos éticos mais polêmicos. Por se tratar de questão central nas pesquisas cujo material provém de sorotecas, será tratado em maior profundidade na abordagem destas.

Os principais FF e FR de cada tipo de estudo são comparados entre si, apresentando-se uma síntese que contribua para subsidiar a escolha do método mais adequado de estudo desses agravos, sob o ponto de vista ético.

\section{Relevância social e estudos epidemiológicos sobre hepatites virais}

O princípio de relevância social de pesquisas epidemiológicas acerca das HV, qualquer que seja o tipo de estudo aplicado, pode ser demonstrado ao se considerar sua magnitude, gravidade e disponibilidade de medidas preventivas e terapêuticas.

Segundo a portaria que institui o Programa Nacional para a Prevenção e o Controle das HV, estas doenças "configuram um grave problema de saúde pública em nosso país ${ }^{5 "}$. Entre as doenças de notificação compulsória, ocupavam o sexto lugar em número de casos notificados no Brasil, em 200I, sendo superadas apenas pela epidemia de dengue e por antigas endemias (malária, tuberculose, leishmaniose e hanseníase) ${ }^{15}$. É interessante observar que corresponderam a I,5\% dos casos notificados, o dobro do que se verificou para casos de AIDS $(0,74 \%)$, apesar de terem sido incluídas na lista nacional de agravos notificáveis em 1996, ou seja, após as demais doenças citadas ${ }^{16}$.

A excepcional estabilidade do VHA contribui para a difusão de epidemias e a alta carga desta doença torna importante o custo indireto do tempo de afastamento do trabalho ${ }^{17}$, enquanto o conhecimento do perfil sociodemográfico dos casos/infecções e o monitoramento da tendência do VHA permitirão identificar áreas de risco, subsidiar estratégias de vacinação de suscetíveis, migrantes e viajantes e avaliar impactos de intervenções sobre seus determinantes, como o saneamento ${ }^{18}$.

As infecções subclínicas por VHB podem evoluir à cronicidade, principalmente ao ocorrerem em idade precoce, sendo que em poucas ocasiões esta etiologia é suspeitada. A existência de 350 milhões de portadores do VHB no mundo - permanentes reservatórios de transmissão da infecção - justifica o investimento em pesquisas que possam contribuir para o melhor entendimento da distribuição contemporânea desta pandemia ${ }^{19}$. Aliados à sua gravidade e magnitude, encontram-se o custo ainda elevado e a limitada eficácia da terapêutica de pacientes crônicos $^{20}$. Agravando ainda mais este quadro epidemiológico, associase ao VHB o vírus defectivo delta, que eleva a letalidade por formas fulminantes da hepatite $B$, além de acelerar o curso, aumentar a freqüência das formas crônicas e reduzir a resposta ao tratamento ${ }^{21}$.

Estimativas da OMS consideram a existência de 170 milhões de pessoas infectadas pelo vírus da hepatite $\mathrm{C}(\mathrm{VHC})$ no mundo, sendo que $80 \%$ a $85 \%$ dos casos podem evoluir à cronicidade, ocupando atualmente o primeiro lugar entre as causas de transplante hepático ${ }^{22,2}$. No Brasil, foram notificados, até 200I, cerca de 20000 casos, tornando-se impossível negar a emergência de mais uma epidemia de gravidade inquestionável ${ }^{15}$.

Existem evidências de que o vírus da hepatite E - de veiculação hídrica e de alta incidência na Índia, México e África ${ }^{23}$ - circula em nosso meio, embora não haja relatos de surtos ${ }^{24}$. Além disso, o VHE encontra, em nosso mosaico socioambiental, condições propícias à sua propagação. 
A relevância de pesquisas sobre estes agravos pode ser justificada ainda pela necessidade de subsidiar estratégias de prevenção e controle, como a vacinação contra as hepatites A e B, a triagem sorológica de doadores de sangue/tecidos/órgãos, a redução de danos entre usuários de drogas e de embasar decisões sobre a aquisição e uso de esquemas terapêuticos mais eficazes, seguros e eficientes.

\section{Aspectos éticos dos estudos epidemiológicos de HV Inquéritos domiciliares de soroprevalência (IDS)}

Os IDS de HV têm como linha mestra a coleta de sangue venoso, após a orientação sobre os procedimentos e objetivos da pesquisa e a assinatura do termo de consentimento informado. Esta amostra de sangue é posteriormente fracionada para que, no soro ou plasma obtidos, sejam pesquisados os marcadores sorológicos específicos para cada etiologia viral.

Os procedimentos diagnósticos utilizados nos IDS são considerados como muito sensíveis, tornando-os mais representativos do perfil epidemiológico de um agravo do que outras estratégias de monitoramento de doenças como os ES e os ERBS25. No entanto, para que os estudos sejam efetivados, necessita-se de elevadas somas de recursos (humanos e materiais) que terminam por dificultar o cumprimento de outra exigência: a de que haja preponderância de benefícios sobre custos. Mesmo com recursos suficientes, as dificuldades operacionais destes estudos podem levar a perdas consideráveis da amostra e possíveis enviesamentos. Por outro lado, estes modelos refletem situações particulares de grupamentos populacionais em relação ao tempo, dificultando a comparação com outros estudos e a análise da tendência secular dos eventos enfocados ${ }^{4}$, sendo limitada sua utilidade (benefício) no monitoramento de tendências. Para contornar esta limitação, seria necessária a realização de IDS sob a forma de estudos multicêntricos e de modo seriado, o que levaria a aumento dos custos e recairia na exigência ética de que os custos superem os benefícios. Assim, a recomendação ética de que os efeitos dos benefícios possam permanecer após seu encerramento torna-se difícil de ser alcançada sem elevação de custos. Considerando que o conhecimento que se pretende obter pode ser conseguido por outros meios, como por meio de ES ou EAS, mais uma exigência ética torna-se difícil de ser cumprida.

Os IDS efetuam coleta de sangue de pessoas virtualmente saudáveis e, ainda que este procedimento seja bastante seguro, não é totalmente isento de risco. Adicionalmente ao risco inerente a esta coleta, está o proveniente do recebimento do resultado do exame. Ao consentir a participação na pesquisa, o sujeito precisa também ter a opção de ser ou não informado dos resultados e dos seus aspectos positivos e negativos.

Uma importante questão ética aqui se coloca. Ao efetuar uma pesquisa em que haja a possibilidade de se identificar portadores assintomáticos de hepatites crônicas B e C, há que se garantir que os sujeitos e seus familiares tenham o acompanhamento, tratamento ou a orientação necessária. Isto onera ainda mais o custo do estudo e evidencia a importância de que estas pesquisas sejam efetuadas em cooperação com os serviços de saúde e de vigilância epidemiológica (VE).

Um aspecto pouco questionado ao se julgar projetos de IDS é a garantia de confidencialidade e privacidade do sujeito da pesquisa na obtenção e divulgação das informaç̃̃es. Na maioria das vezes, os IDS, para serem representativos, trabalham com amostras populacionais da ordem de milhares, o que exige equipes compostas por grande número de profissionais bem treinados. Entretanto, apesar dos cuidados que possam ser tomados, a quebra de sigilo tende a ocorrer com mais freqüência quanto maiores forem as equipes de trabalho ${ }^{26}$.

Com as ressalvas efetuadas, predominam como pontos de força dos IDS a autonomia do sujeito da pesquisa, a metodologia adequada, o respeito aos valores culturais, sociais, morais, religiosos e éticos, bem como aos hábitos e costumes das comunidades e a viabilidade de comunicação às autoridades sanitárias dos resultados da pesquisa.

As principais fragilidades são: o custo mais elevado do que os benefícios, a possibilidade de que o conhecimento possa ser obtido por outros meios, a dificuldade de garantir a confidencialidade e a privacidade e de assegurar que os sujeitos da pesquisa e seus familiares tenham acompanhamento, tratamento ou orientação, tendo em vista que o próprio sistema de saúde apresenta falhas neste sentido.

\section{Estudos com registros de bancos de sangue (ERBS)}

As estimativas de prevalência de hepatites B e $C$ com base nos registros de bancos de sangue, ou seja, nos resultados da triagem sorológica de doadores de sangue, vêm sendo utilizadas há pelo menos três décadas ${ }^{27}$, inclusive pela Organização Panamericana de Saúde ${ }^{6}$. Úteis por permitirem o acompanhamento da tendência dessas infecções na população de doadores, são alvos de críticas pela limitação de representatividade das informações, tendo em vista que os doadores de sangue restringem-se ao grupo etário de 18 a 65 anos e são, na sua maioria, do sexo masculino, e por possíveis vieses relacionados à captação de doadores e à triagem clínica (que exclui doadores que referem ter tido hepatite), dentre outros.

Sob o ponto de vista ético, podem ser justificadas em termos metodológicos por permitirem monitorar a tendência das infecções pelo VHB e VHC em uma significativa amostra populacional (ainda que enviesada), sem risco adicional ao sujeito da pesquisa (o doador) e com acréscimo mínimo de custo (o de resgate dos registros). Tendo em vista que os vieses de seleção deste tipo de estudo são os mesmos e se mantêm ao longo do tempo, na maioria dos bancos de sangue, a homogeneidade dos dados permite efetuar comparações entre diversas regiões e acompanhar as estimativas de soroprevalência em períodos regulares. E, embora o conhecimento que se pretende obter possa ser obtido por outro meio, este é um dos meios de menor risco e custo.

Quanto ao consentimento livre e esclarecido (autonomia) do sujeito da pesquisa, embora seja possível obtê-lo - informando-se ao doador que os dados obtidos poderão ser utilizados em futuras pesquisas, preservando-se sua identidade - não é habitualmente requerido. Pesquisas a partir de bancos de dados, desde que não divulguem informações que permitam identificar os sujeitos, podem ser dispensadas da obtenção do consentimento informado ${ }^{28}$.

Este tipo de estudo, portanto, apresenta como pontos de força: a possibilidade de promover a beneficência da comunidade, por meio do monitoramento da tendência das infecções por VHB e VHC em doadores de sangue (sujeitos da pesquisa), que também podem contar, além do diagnóstico, com o acompanhamento, tratamento e orientaçãa 29 ; o fato de que os efeitos destes benefícios permanecem por 
prolongado período, já que as informações servirão ao acompanhamento temporal e espacial do comportamento epidemiológico dessas infecções; o baixo custo adicional; a segurança de confidencialidade e privacidade do sujeito da pesquisa na obtenção e divulgação das informações, tendo em vista que o próprio sistema de registro dos bancos de sangue possui mecanismos de garantia de sigilo dos doadores; e o fato de que os danos possíveis são inerentes à doação e não à pesquisa em si. Outro ponto de força é que a comunicação dos resultados da pesquisa às autoridades sanitárias está praticamente institucionalizada e vem contribuindo para o melhor conhecimento dessas epidemias.

Como ponto de fragilidade importante está a limitação de representatividade amostral, com vieses de seleção por sexo e faixa etária, e os secundários à triagem clínica que exclui os doadores com história pregressa ou atual de hepatites.

\section{Estudos sentinelas (ES)}

São aqueles em que se concentra esforços na obtenção de informações epidemiológicas sobre um agravo à saúde, por meio de um ou mais serviços ou profissionais de saúde selecionados ${ }^{30}$. Nos serviços de saúde, podem ser aplicados como estratégia de monitoramento de agravos, sob a forma de vigilância sentinela, sendo efetuadas adequações metodológicas de acordo com os objetivos a que se propõe e segundo o agravo, a estrutura das unidades de saúde, as características sociodemográficas da população alvo, e a área de abrangência.

ES para monitorar a tendência da infecção pelo HIV, utilizando amostras de soro coletadas na rotina de unidades de saúde, vêm sendo realizados nos EUA desde 1987. Quanto aos procedimentos éticos, verifica-se que a opção preferencial nestes estudos, para a coleta de amostras e de dados, é a anônima não vinculada, na qual não existe interação pesquisador/população selecionada ${ }^{31,32,33}$, prescindindo do consentimento informado. Entretanto, uma estratégia de obtenção deste consentimento, garantindo-se o anonimato e a não vinculaçãa, pode ser a de sensibilização da clientela seguida da obtenção do prévio consentimento informado de todos os clientes do serviço, venham eles a ser incluídos ou não no estudo ${ }^{32}$.

Nos ES em que se trabalha com amostras de demanda de serviços, o cuidado para que o sujeito não saiba se está ou não participando de uma dada pesquisa é necessário para evitar vieses de auto-seleção. Embora os sentidos atribuídos às HV não aparentem ter a intensidade das representações sociais da AIDS, podem suscitar medo e discriminação $0^{34}$. Entretanto, a exigência de consentimento formal pode acarretar sobrecarga aos profissionais dos serviços e retardamento da rotina. Esta exigência poderia ainda gerar uma possível desconfiança nos pacientes que, ao colherem sangue para exames de rotina em outras ocasiões, nunca haviam se questionado sobre a possibilidade de a sobra de amostra ser utilizada para outros fins. Esta dúvida induzida poderia originar outra: sendo a AIDS, atualmente, o evento mais freqüentemente vinculado à necessidade de exame de sangue para diagnóstico, a analogia seria quase inevitável. Mesmo que um tempo considerável fosse despendido para esclarecer este ponto, algum viés de autoseleção seria introduzido.

Pappaioanou et al. ${ }^{31}$, apoiando-se no Código Federal Americano, alegam que, nos estudos em que não há interação entre o pesquisador e nenhum risco para o sujeito da pesquisa, o consentimento informado pode ser dispensado.

O Conselho Federal de Medicina ${ }^{35}$, respondendo à consulta do Conselho Regional de Medicina de São Paulo acerca deste assunto, concluiu que "a realização de exames sorológicos com finalidade de inquérito epidemiológico... coordenado por instituições oficiais não fere os artigos do CFM, desde que se utilize o método anônimo não relacionado". Assinala ainda que "... além dos inquestionáveis benefícios do ponto de vista da saúde pública, com o respaldo, inclusive, da Organização Mundial da Saúde, garante integralmente a privacidade do indivíduo, haja vista que o exame não é identificado".

Por outro lado, nos casos em que a coleta de amostras é anônima não vinculada, como o próprio pesquisador desconhece a identificação dos sujeitos, estes não podem obter seus resultados. Nesses estudos e nas situações em que medidas individuais de acompanhamento, tratamento ou orientação são necessárias, cria-se um impasse que precisa ser melhor discutido ${ }^{12}$. Conforme determina a Resolução CNS n ${ }^{\circ}$ |96/ 96, estas medidas individuais devem ser contempladas nas pesquisas em seres humanos. Na VE (ativa ou passiva) oficial, estas medidas também deveriam estar incluídas, em atenção ao princípio básico de saúde pública de que a busca de dados deve ser seguida de um diagnóstico de situação e de uma tomada de decisão no sentido de prevenir e controlar o possível evento adverso à saúde.

É importante observar, no entanto, que existem situações em que medidas individuais não são necessárias (ou são limitadas a determinados grupos), como por exemplo, na pesquisa de marcadores sorológicos que revelam a presença ou ausência de imunidade a determinado vírus. O benefício ao sujeito da pesquisa, proveniente do conhecimento deste status sorológico, é possível nos casos em que medidas preventivas específicas para os suscetíveis (infecção e imunidade ausentes) estejam indicadas e disponíveis, como a vacinação contra a hepatite B de menores de 20 anos e de pessoas mais expostas ao risco de adquirir esta infecção (p.ex.: UDI, profissionais do sexo, profissionais de saúde, etc) e de vacinação contra a hepatite $A$ de portadores de hepatites crônicas. Ressalte-se ainda que a implementação de medidas preventivas (saneamento básico, controle da qualidade do sangue, vacinação e distribuição de seringas descartáveis e preservativos) é um dos possíveis benefícios coletivos desta pesquisa.

Quanto aos indivíduos imunes detectados, não mais expostos ao risco de adquirir infecções por vírus de hepatites (por já terem sido suas vítimas) evidenciam, de modo contundente, a necessidade de preveni-las. Ao indivíduo imune, pouco benefício traria o conhecimento deste estado de imunidade; podendo até causar-lhe dano, pelo entendimento equivocado de que a "resistência" às hepatites pesquisadas oferece a mesma garantia para as restantes.

Entretanto, nas pesquisas em que se objetive detectar casos de hepatite aguda ou crônica, medidas individuais de acompanhamento, tratamento ou orientação são necessárias, sendo portanto impraticável o uso da coleta anônima não vinculada ${ }^{12}$. Nessas situações, uma alternativa ética pode ser a de obtenção de consentimento informado antes da coleta de sangue de rotina de todos os clientes (sujeitos ou não da pesquisa), momento em que também fariam a opção por serem ou não informados acerca dos resultados. Na seleção das amostras de soro dos sujeitos da pesquisa, sua identificação pode ser feita de forma 
codificada, à semelhança da metodologia dos centros de testagem anônima para o HIV (CTA-HIV), e utilizando-se linguagem eletrônica encriptada, de modo que as pessoas possam ser contatadas para receberem os resultados ${ }^{36}$.

Socialmente, estes estudos justificam-se por reduzir o custo dos IDS, sendo que, cientificamente, garantem a qualidade dos resultados e 0 respeito à ética ${ }^{37}$. Esta metodologia permite complementar as informações da VE, compreender a dinâmica da distribuiç̧ão contemporânea das hepatites, promover a sensibilização política e a mobilização de financiamentos, subsidiando o gerenciamento de programas de prevenção, no sentido de otimizar a aplicação de recursos.

Quanto ao princípio da não maleficência, na situação de inexistência de interação pesquisador/população selecionada ou naquela em que há garantia de anonimato pela adoção do sistema de sigilo dos CTA-HIV, não há risco, ao indivíduo, de qualquer natureza, advindo dos procedimentos adotados. Convém lembrar que não se efetua nenhuma coleta de material humano específica para as finalidades da pesquisa. Apenas se utilizam amostras excedentes de sangue coletado por outros motivos. Portanto, atividades que possam levar a danos da dimensão física, psíquica, moral, intelectual, social, cultural ou espiritual dos sujeitos da pesquisa não são desenvolvidas.

Os pontos de força mais significativos desta metodologia são: a possibilidade de monitoramento da tendência das infecções por vírus das hepatites, com custo inferior ao dos IDS; o fato de que os efeitos destes benefícios podem permanecer por período prolongado, já que as informações servirão ao acompanhamento espaço-temporal do comportamento epidemiológico dessas infecções; o baixo custo operacional, visto que são aproveitados os recursos humanos dos laboratórios de análises clínicas para a coleta das amostras de soros; a segurança de confidencialidade e privacidade do sujeito da pesquisa na obtenção e divulgação das informações; e o fato de que os danos possíveis são inerentes à coleta de amostra de sangue para exame e não à pesquisa em si.

A comunicação dos resultados da pesquisa às autoridades sanitárias pode ser institucionalizada, complementando de modo rotineiro os dados da VE e proporcionando um monitoramento regular e padronizado da soroprevalência das HV.

Como ponto de fragilidade está a limitação de representatividade amostral, tendo em vista que as amostras são oriundas de demanda espontânea a serviços de saúde. Entretanto, esta limitação pode ser contornada por meio de estimativas amostrais que prevejam a estratificação por sexo, faixa etária e bairro de residência, garantindo a representatividade demográfica e socioambiental do grupamento populacional e área monitorados. Outra consideração quanto à representatividade amostral relaciona-se aos critérios de inclusão/exclusão dos sujeitos da pesquisa quanto à presença ou ausência de história atual ou pregressa de HV. Uma estratégia para controlar este possível viés seria a coleta desta informação espećífica junto ao sujeito da pesquisa ou a utilização da elevação das transaminases como traçadora da existência de comprometimento hepático.

\section{Sorotecas}

A estocagem de material biológico para fins de pesquisa, revisão diagnóstica e capacitação de profissionais de saúde é efetuada há longo tempo, como no estudo de cadáveres (na íntegra ou em partes) ou de coleções de lâminas de biópsias. Com o desenvolvimento das técnicas de refrigeração, tem se tornado virtualmente possível a manutenção com preservação das características originais dos mais diversos espécimens por extensos períodos de tempo.

Estas coleções de material biológico podem contribuir para: o estudo da história natural de doenças; a identificação de patógenos nas investigações epidemiológicas de surtos, permitindo, inclusive, detectar agentes etiológicos desconhecidos na ocasião em que a epidemia se propaga; estimar o risco de transmissão de uma infecção e determinar sua prevalência. Sir Richard Doll, durante painel no EPIRIO-98, ao ser questionado sobre o tipo de estudo epidemiológico que gostaria de realizar na época, respondeu que faria um estudo prospectivo com um grande número de indivíduos, entrevistando-os sobre seus hábitos de vida e fatores de risco, e colhendo suas amostras de sangue para serem armazenadas e congeladas, a fim de que fosse possivel posteriormente identificar determinantes de diversos agravos à saúde $e^{38}$

Ou seja, a disponibilidade de material biológico viável estocado permite estudar agravos à saúde ocorridos no passado, aplicando-se recursos tecnológicos do presente e do futuro. Alguns dos benefícios resultantes do uso de amostras biológicas estocadas em pesquisas mostraram-se de grande relevância social. Dentre estes, na década de 60, estudos com biópsias de lesões pré-cancerígenas de colo uterino levaram à instituição do exame papanicolaou na rotina, que tem desempenhado importante papel no diagnóstico precoce, prevenção e tratamento do câncer de colo ${ }^{39}$.

Entretanto, esta metodologia de pesquisa tem suscitado polêmica devido a questões éticas, principalmente quanto à autonomia do sujeito da pesquisa e sobre a exclusividade do uso do material biológico e dos dados obtidos para a finalidade prevista no protocolo da pesquisa. $\mathrm{O}$ cerne da questão não está apenas na estocagem do material em si, mas na informação que poderá ser obtida a partir das amostras, colocando em risco o direito de privacidade e confidencialidade. Diante da possibilidade do uso indiscriminado de espécimens armazenados, é inegável a necessidade de estabelecer critérios e limites para a manutenção de sorotecas. Porém, a própria resolução CNS n 196/96 recomenda a ponderação entre riscos e benefícios para avaliar a beneficência de uma pesquisa, sendo esta admissível, apesar dos riscos potenciais, quando: "oferecerem elevada possibilidade de gerar conhecimento para entender, prevenir ou aliviar um problema que afete o bem-estar dos sujeitos da pesquisa e de outros indivíduos; o risco se justifique pela importância do benefício esperado; o benefício seja maior, ou no mínimo igual, a outras alternativas já estabelecidas para a prevenção, o diagnóstico e 0 tratamento" ${ }^{2}$. Esta resolução regulamenta ainda outros aspectos relacionados à garantia de confidencialidade dos dados (p.ex.: itens III.3.i. e IV. I.g.) e acerca do direito à indenização (item V.7.). A Comissão Nacional de Ética em Pesquisa deve elaborar uma proposta com normas específicas sobre o armazenamento de material biológico ${ }^{13}$.

Ao se coletar amostras de soro para uma pesquisa com o propósito de mantê-las armazenadas por período indefinido a fim de que possam ser aproveitadas em outros estudos, com finalidades diversas das previstas no protocolo, o sujeito da pesquisa deveria ser informado acerca deste objetivo. Ser esclarecido de que é livre para consentir ou 
recusar a proposta, optando por ser informado (ou não) sobre os resultados de pesquisas futuras pode garantir o direito à autonomia do sujeito da pesquisa. Por outro lado, torna-se inviável prever todas as pesquisas que poderão ser realizadas e seus riscos potenciais, sendo desta maneira impossível para o sujeito avaliar se consente ou não na estocagem de seu material biológico.

Os argumentos de maior força a favor da manutenção de sorotecas são: a possibilidade de detectar e prevenir doenças e melhorar as condições de saúde do próprio sujeito e da população, o direito à liberdade de pesquisa e o interesse da sociedade no desenvolvimento científico e tecnológico. Alguns interesses podem também ser relacionados: interesse social e econômico no desenvolvimento da biotecnologia; interesse pessoal do sujeito da pesquisa em contribuir com o progresso científico; interesse pessoal na comercialização de seu material biológico ou em sua manutenção visando beneficiar familiares ou herdeiros; e interesse na liberdade reprodutiva (direito à escolha de ter filhos ou não, quando, quantos e com que características $)^{39}$.

Do outro lado, estão os argumentos de maior peso favoráveis à restrição de acesso e controle de material biológico estocado. Os relativos aos danos potenciais que podem ser causados pela divulgação inconseqüente de informações extraídas das amostras (discriminação ocupacional, estigmatização individual, familiar ou étnica) e pela clonagem. Alguns dos aspectos favoráveis à manutenção de sorotecas, acima citados, também podem interessar ao maior controle destes estoques como, por exemplo, o interesse comercial dos administradores da soroteca ferindo o direito à propriedade do sujeito-fonte da amostra.

Resumindo, os principais aspectos éticos envolvidos com a manutenção de sorotecas relacionam-se, de um lado, aos benefícios que poderão advir de pesquisas futuras com as amostras estocadas e, de outro, aos danos que a divulgação indiscriminada de informações possa trazer aos sujeitos da pesquisa. Desta questão, emerge naturalmente outra: as amostras deverão ser identificadas ou não?

Caso as amostras não sejam identificadas, os benefícios como prevenção, diagnóstico e tratamento precoce de algumas doenças não poderão ser oferecidos aos sujeitos da pesquisa, visto que não será possível identificá-los. Nesta situação, uma política de sorotecas anônimas seria um impedimento inaceitável à obrigação tanto da sociedade quanto do pesquisador de prevenir danos ${ }^{39}$. Por outro lado, o direito à autonomia também precisaria ser preservado e, para tal, o indivíduo deverá ser consultado e ser livre para tomar a decisão de ter ou não sua amostra identificada e de ser ou não informado sobre resultados de futuras pesquisas.

Mas, essa questão não é assim tão simples. Caso as amostras sejam identificadas, como garantir que o direito à autonomia, privacidade e confidencialidade seja preservado? Em geral, superestima-se o valor do consentimento informado, visto que este consentimento é falho em se tratando de futuros protocolos. Algumas alternativas ao consentimento informado tradicionalmente utilizado têm sido aventadas: o consentimento em branco, o seletivo e o coletivo. Consentir em branco equivale à concordância com a utilização do material biológico fornecido para qualquer finalidade conhecida ou a ser incorporada no futuro. O consentimento seletivo, acompanhado de identificação codificada das amostras, permite ao sujeito da pesquisa definir previamente critérios para futuros usos (inclusive de descarte) e conhecimento de resultados (Clayton, 1995) ${ }^{40}$. O coletivo talvez seja a prática mais apropriada em alguns contextos socioculturais, como para grupos minoritários vulneráveis à discriminação étnica ${ }^{4}$.

Ultrapassando a questão de se manter ou não sorotecas, cabe refletir sobre o que fazer com as sorotecas já existentes. Em muitos casos, os indivíduos que forneceram as amostras estocadas, embora pudessem ter concordado na coleta da amostra, sequer tinham idéia de que seu material seria ou poderia ser estocado e, muito menos, que poderia ser utilizado em propostas futuras, incluindo a completa caracterização do genoma individual. Por exemplo, as amostras de sangue coletadas desde 1970 de quase todas as pessoas nascidas em hospitais nos EUA, com o propósito de realizar screenings para alterações genéticas. Em alguns estados americanos, estas amostras estão sendo estocadas indefinidamente, em outros são descartadas após cinco anos, não havendo portanto uma política uniforme em relação a esta conduta ${ }^{39-1}$.

No caso de sorotecas em que o consentimento informado foi o tradicional, e é possível identificar os sujeitos-fontes das amostras, seria interessante providenciar a obtenção do consentimento seletivo, embora o custo deste procedimento possa ser elevado. Naquelas em que não há possibilidade de identificação do sujeito, e o CEP considerou que não existe a possibilidade de identificação étnica e danos potenciais a um grupo social, nem outros advindos do novo protocolo de pesquisa, as amostras poderiam ser utilizadas.

Nas sorotecas em que nenhum consentimento foi obtido, cabe ao CEP investigar se o que ocorreu foi apenas uma omissão ou violação de direitos humanos. Na primeira opção, caberia providenciar a obtenção do consentimento seletivo e utilizar as amostras. $\mathrm{Na}$ segunda, estas amostras deveriam ser destruídas ${ }^{39}$.

Predominam, portanto, como pontos de força dos EAS: a garantia de retorno dos benefícios às pessoas e comunidades, contribuindo para a melhoria das condições de saúde da coletividade; a possibilidade de comunicação às autoridades sanitárias dos resultados, garantindo aos sujeitos da pesquisa as condições de acompanhamento, tratamento ou orientação; a preponderância de benefícios sobre riscos e custos, evitando-se novas exposições do sujeito a danos à sua integridade física e gastos com a coleta de novo material; a garantia de que os efeitos dos benefícios podem permanecer mesmo após o encerramento; e a metodologia adequada. $\mathrm{O}$ direito à autonomia, privacidade e confidencialidade pode ser garantido por meio da obtenção do consentimento livre, esclarecido e seletivo, com codificação da identidade da amostra. E, ainda, o respeito aos valores culturais, sociais, morais, religiosos e éticos, bem como aos hábitos e costumes das comunidades pode também ser suprido por meio do consentimento coletivo.

A fragilidade mais evidente é que este tipo de pesquisa tem como condição essencial que o material biológico e os dados obtidos em uma pesquisa sejam utilizados para outras finalidades e em outros estudos (delineados ou não). Isto exige, portanto, que as equipes que administram sorotecas atuem dentro de rigorosos princípios éticos. Outra fragilidade menos consistente é que o conhecimento que se pretende obter pode, algumas vezes, ser obtido por outro meio. Entretanto, possibilidades de enriquecimento ao conhecimento científico e tecnológico sequer imaginadas podem ser desvendadas pelo estudo de amostras biológicas estocadas. 
Gaze R et al.

\section{Conclusão}

O debate acerca da abrangência e limites da pesquisa científica e da aplicação de recursos tecnológicos sob a ótica da ética vem se desenvolvendo há algum tempo. Princípios e diretrizes éticas em pesquisas com seres humanos estão regulamentados. Entretanto, a diversidade da aplicaçãa de tecnologias e a velocidade com que são criadas exigem discussões específicas e aprofundadas a cada nova situação ${ }^{42}$.

Este artigo discutiu os aspectos éticos de quatro tipos de estudo utilizados para conhecer o comportamento epidemiológico das HV: IDS, ES, ERBS e EAS. Mais do que analisar os aspectos éticos de cada estudo ou estratégia de monitoramento, oferece um material útil para subsidiar a escolha de um determinado método.

Contém argumentos que, além de contribuírem para o embasamento de processos éticos e ajustes metodológicos de pesquisas, possibilitam ampliar reflexões sobre os temas abordados e construir novos conceitos.

\section{Conflito de interesse: não há}

\section{SUMMARY}

\section{Ethical issues about Seroprevalence studies on VIRAL HEPATITIS}

BACKGROUND. Epidemiologicalstudies on viral hepatitis(VH) usingnew technologies raise ethical issues especially concerning community-based studies on seroprevalence (CSS), sentinel surveillance-based studies (SBS) the use of blood-bank registers (BBR) and serum stocks (SS).

Methods. Positive (PA) and negative (NA) aspects of these different designs are discussed, pointing to alternatives, according to Resolution CNSn'196/96.

RESULTS. Priority for research is justified by VH magnitude, severity, and vulnerability, and need for development of diagnosis/therapy protocols and prevention/control strategies. With respect to CSS, PA was identified as: subject autonomy; adequate samples and as NA: costs override benefits, and availability of information from other sources. In relation to SBS, PA are: VH monitoring has lower operational costs than CSS; absence of additional injuries to subject; while NA is: relative restriction of representativeness. For BBR, PAis: the low cost of monitoring of $\mathrm{HBV} / \mathrm{HCV}$ in blood donors and with no additional risk. PA has limited representativeness. SS studies present as PA: benefits higher than risks/costs; possibility of identification of new morbidity and offering of adequate diagnosis and treatment. NA is: biological material and research data can be usedfor other researches.

CONCLUSION. The choice of study designs must take into account arguments for ethical investigation and consensus on the use of new technology. [Rev Assoc Med Bras 2006; 52(3): 162-9]

KEY wORDs: Hepatitis. Ethics. Stocked sera, Seroprevalence studies.

\section{REFERÊNCIAS}

I. Nübling CM, Unger G, Chudy M, Raia S, Löwer J. Sensitivity of HCV core antigen and HCV RNA detection in the early infection phase. Transfusion 2002:42(8): 1037-45.

2. Centers for Disease Control and Prevention. Recommendations for prevention and control of Hepatitis C Virus (HCV) Infection and HCV- related chronic disease. MMWR 1998; 47(RR 19): I-39. Avaiable from: http://www.cdc.gov/mmwr/preview/mmwrhtml/00055 I 54.htm.

3. Pergoraro O. Horizonte da bioética. Jornal CREMERJ 200 I; | 4( I 35): I 2.

4. Andrade ALSS, Martelli CMT, Pinheiro ED, Santana CL, Borges FP, Zicker F. Rastreamento sorológico para doenças infecciosas em banco de sangue como indicador de morbidade populacional. Rev Saúde Pública 1989; 23(I):20-5.

5. Martelli CMT, Andrade ALSS, Cardoso DDP, Almeida e Silva S, Zicker F. Considerações metodológicas na interpretação do rastreamento sorológico da hepatite $B$ em doadores de sangue. Rev Saúde Pública 1991;25(I): I I-6.

6. Hadler SC, Fay OH, Pinheiro F, Maynard JE. La hepatitis en las Américas: Informe del grupo colaborador de la OPS. Bol Of Sanit Panam 1987; I 03(3): I 85-209.

7. Murphy EL, Brysman S, Williams AE, Co-Chien H, Schreiber GB, Ownby $\mathrm{HE}$, et al. Demographic determinants of hepatitis $C$ virus seroprevalence among blood Donors. JAMA 1996;275(I 3):995- 1000.

8. Dubois F, Desenclos JC, Mariotte N, Goudeau A. Hepatitis C in a French population-based survey, 1994: seroprevalence, frequency of viremia, genotype distribution, and risk factors. J Hepatol 1997;25(6): | 490-6.

9. Valleron AJ, Bouvet E, Garnerin P, Ménarès J, Heard I, Letrait S, et al. A computer network for the surveillance of communicable diseases: the French experiment. Am J Public Health 1986; 76(I I): 1 289-92.

10. Centers for Disease Control and Prevention 1996. Viral hepatitis surveillance program, 1993. Report n. 56. Atlanta. [cited Apr. 1996]. Avaiable from: http:// www.cdc.gov/ ncidod/ diseases/ hepatitis/ h96surve.htm.

11. Chamberland ME. Surveillance for bloodborne infections. Thromb Haemost. 1999; 82(2):494-9.

12. Brasil. Conselho Nacional de Saúde. Resolução n 196 de 10 de outubro de 1996: "Aprova diretrizes e normas regulamentadoras de pesquisas envolvendo seres humanos". Bioética 1996;4(2): 15-25.

13. Hossne, W.S. Armazenamento de materiais [Editorial] Cad Ética Pesq 2003;6(I2):3-4.

14. Brasil. Portaria Ministério da Saúde n 263/GM de 2002. Institui, no âmbito do SUS, o Programa Nacional para a Prevenção e o Controle das Hepatites Virais, a ser desenvolvido de forma articulada pelo Ministério da Saúde e pelas Secretarias de Saúde dos estados, Distrito Federal e municípios. Fev 2002.

15. Fundação Nacional de Saúde. Vigilância Epidemiológica. Série Histórica de Doenças de Notificação Compulsória por UF, 1980 a 2001 . [citado nov 2003. Disponível em: http://www.funasa.gov.br/epi/pdfs/sh_dnc_uf_ 1980_2001.pdf.

16. Brasil. Portaria Ministério da Saúde n. ${ }^{\circ}$ I 00 de 1996. Lista Nacional de Doenças de Notificação Compulsória. Diário Oficial União 1996; 27 maio.

17. Lemon SM. Inactivated hepatitis A virus vaccines [Editorial] J Hepatol 1992; I 5(6): I194-7.

18. Gaze R. Hepatites virais: alfabeto submerso [dissertação]. Rio de Janeiro: Núcleo de Estudos de Saúde Coletiva, Universidade Federal do Rio de Janeiro; 1999.

19. World Health Organization. 2002. Department of Comunicable Disease Surveillance and Response. Hepatitis B - an introdution. Avaiable from: http:// www.who.int/ emc-documents/ hepatitis/ docs/ whocdscsrlyo 20022/introduction/introduction.html.

20. Alberti A, Brunetto MR, Colombo M, Craxì A. Recent progress and new trends in the treatment of hepatitis B. J Med Virol 2002;67(3):458-62.

21. Weltman MD, Brotodihardjo A, Crewe EB, Farrell GC, Bilous M, Grierson JM, et al. Coinfection with hepatitis B and C or B, C and delta viruses results in severe chronic liver disease and responds poorly to interferon-alpha treatment. J Viral Hepat 1995; 2(I):39-45.

22. World Health Organization. 2000. Information. Fact Sheet $n^{\circ} 164$. Hepatitis C. Revised October 2000. Avaiable from: http://www.who.int/ inf-fs/en/fact I 64.html.

23. Centers for Disease Control and Prevention.. 2001. Geographic distribution of hepatitis E. Avaiable from: http:// www.cdc.gov/ ncidod/ diseases/ hepatitis/slideset/hep_e/ slide_5.htm. 
24. Trinta KS, Liberto MIM, Paula VS, Yoshida CFT, Gaspar AMC. Hepatitis E virus infection in selected Brazilian populations. Mem Inst Oswaldo Cruz 2001;96(I):25-9. Avaiable from: http://www.scielo.br/ scielo.php? script = sci_arttext\&pid = S0074-02762001000100004\& Ing $=$ en\& $\mathrm{nrm}=$ isso.

25. St. Louis ME, Olivo N, Critchley S, Rauch KJ, White CR, Munn VP. et al. Methods of Surveillance for HIV Infection at U.S. Sentinel Hospitals. Public Health Rep 1990; 105(2): I 40-6.

26. Victora CS. Aspectos práticos do planejamento de inquéritos epidemiológicos. RBMGC 1987; I ( I): | 4-20.

27. Szmuness W, Dienstag JL, Purcell RH, Stevens CE, Wong DC, Ikram H, et al. The prevalence of antibody to hepatitis A antigen in various parts of the world: a pilot study. Am J Epidemiol 1977; I06(5):392-8.

28. Thurston WE, Burgess MM, Adair CE. Commentary: ethical issues in the use of computerized databases for epidemiologic and other health research. Chronic Dis Can 1999;20(3): |27-3I.

29. ANVISA - Agência Nacional de Vigilância Sanitária. Resolução RDC n I 53, de 14 de junho de 2004. Determina o regulamento técnico para os procedimentos hemoterápicos, incluindo a coleta, o processamento, a testagem, o armazenamento, o transporte, o controle de qualidade e o uso humano de sangue, e seus componentes, obtidos do sangue venoso, do cordão umbilical, da placenta e da medula óssea. Diário Oficial União. Disponível em: http://e-legis.bvs.br/leisref/public/showAct.php? id $=$ | | 662. [Citado 24 nov 2004].

30. Pereira MG. Vigilância Epidemiológica. In: Epidemiologia: teoria e prática. Rio de Janeiro: Guanabara Koogan; 1995. p.449-82.

3 I. Pappaioanou M, Dondero TJJr., Petersen LR, Onorato IM, Sanchez CD Curran JW. The family of HIV seroprevalence surveys: objectives, methods, and uses of sentinel surveillance for HIV in the United States. Public Health Rep 1990; 105(2): I I3-9.

32. Alary M, Joly Jr., Parent R, Fauvel M, Dionne M. Sentinel hospital surveillance of HIV infection in Quebec. CMAJ 1994; I 5 I (7):975-8I.

33. Sherlock CH, Strathdee SA, Le T, Sutherland D, O'shaughnessy MV, Schechter MT. Use of pooling and outpatient laboratory specimens in an anonymous seroprevalence survey of HIV infection in British Columbia, Canada. AIDS 1995; 9(8):945-50.

34. Tura LFR, Madeira MC, Gaze R. Representações sociais das hepatites virais e suas implicações nas práticas educativas de prevenção. Cad Saúde Coletiva 2002;2(2): I 20-36

35. Conselho Federal de Medicina. Processo-Consulta CFM n 2947/95. Projeto Vigilância Sentinela de HIV. Brasília; 1996.

36. Ministério da Saúde. Coordenação Nacional de DST e Aids. Diretrizes dos Centros de Testagem e Aconselhamento. Manual. Brasília: Coordenação Nacional de DST e Aids; 1999.

37. Gaze R, Carvalho DM, Luiz RR, Servino VRR, Berro OJ, Bravim Y. Laboratórios Sentinelas: uma proposta para o monitoramento das infecções pelos vírus das hepatites A e B. IESUS 2000;9(I):5-21.

38. Victora C. Richard Doll: Epidemiologia moderna exige colaboração entre pesquisadores. Temas (São Paulo) 1998;16:25. (Apresentado no IV Congresso Brasileiro de Epidemiologia).

39. Buchanan A. An ethical framework for biological samples Policy. National Bioethics Advisory Comission 2002. Avaiable from: http//onlineethics. org/reseth/nbac/buchanan.html.

40. Clayton EW, Steinberg KK, Khoury MJ, Thomson E, Andrews L, Kahn MJ, Kopelman LM, Weiss JO. Informed consent for genetic research on stored tissue samples. JAMA 1995;274(22): I 786-92.

41. Resolução Conselho Nacional de Saúde n 304 de 2000. "Aprova Normas para pesquisas envolvendo seres humanos - área de povos indígenas". Cadernos de Ética em Pesquisa 2000; III (6):25-27. 9 ago 2000.

42. Fortes PAC. Bioética e saúde pública: tópicos de reflexão para a próxima década. O Mundo Saúde 2000;24(I ):3 I-8.

Artigo recebido: 27/I2/2004

Aceito para publicação: 16/1 I/2005 